\title{
Human Polymorphisms as Clinical Predictors in Leprosy
}

\author{
Ernesto Prado Montes de Oca \\ Pharmaceutical and Medical Biotechnology Unit, Research Center in Technology and Design Assistance of Jalisco State, \\ National Council of Science and Technology, 44270 Guadalajara, JAL, Mexico
}

Correspondence should be addressed to Ernesto Prado Montes de Oca, eprado@ciatej.net.mx

Received 16 August 2011; Revised 11 October 2011; Accepted 20 October 2011

Academic Editor: Marcelo Távora Mira

Copyright () 2011 Ernesto Prado Montes de Oca. This is an open access article distributed under the Creative Commons Attribution License, which permits unrestricted use, distribution, and reproduction in any medium, provided the original work is properly cited.

\begin{abstract}
Genetic and serum markers in human host can predict leprosy susceptibility per se as well as be useful in classification and/or prediction of clinical variants and immunological responses in leprosy. Adequate and timely assessment of potential risks associated with these 38 host leprosy genes could diminish epidemiological burden and improve life quality of patients with this still prevalent mycobacterial disease.
\end{abstract}

\section{Introduction}

In recent years, evidence has accumulated for so-called human "multidisease susceptibility genes" that play a role in several infectious and noninfectious diseases [1], and genes presumably more specific on its clinical impact when dysfunctional, that probably do not predispose to the disease per se but to a clinical phenotype when the disease is already present [2]. A decline in leprosy research, probably for the erroneous belief that the battle is won, has left unanswered questions regarding the exact mechanism of disease infection and progression. Addressing these questions could help in the final eradication of leprosy [3].

Human leprosy (or Hansen disease) is a chronic granulomatous infectious disease caused by the obligate intracellular organism Mycobacterium leprae $[4,5]$. Leprosy is still an important health problem worldwide, with the highest incidences in Asia, Africa, and Latin America [6]. In 2008, $\sim 250,000$ new cases of leprosy were reported to World Health Organization [7]. The high concordance rates for leprosy infection when monozygotic and dizygotic twins are compared $(84.55 \%$ versus $18.35 \%$, resp., media of two independent reports) [7] as well as loci that are linked or associated with leprosy, reveal a strong genetic component in the susceptibility and response to the infection with $M$. leprae. Furthermore, complex segregation analyses suggest an oligogenic model of leprosy susceptibility, with a few major genes influencing disease and several additional genes and variations causing subtle effects on disease outcome [8]. The origin of transmission of $M$. leprae is mainly from untreated lepromatous patients [9] and the people most probable infected (leprosy per se) are patient's contacts whose carry susceptibility alleles in loci 20p12 [10], TNFA [11], as well as PARK2 and PACRG genes [12]. Genetic variants in human host, mainly single nucleotide polymorphisms (SNPs) can predict susceptibility to leprosy per se and to clinical variants when leprosy is already present $[2,8$, 13]. Even when death due to leprosy, caused by laryngeal obstruction, is uncommon [14], adequate and opportune detection of potential risks could diminish epidemiological burden and improve life quality of patients with this still unerradicated mycobacterial disease.

\section{Leprosy Classification}

2.1. Ridley-Jopling Classification. Once the infection in the patient is confirmed, it is important to classify leprosy in order to determine the appropriate treatment and predict risk of complications [9] as physical deformities, sensorial loss, and permanent nerve damage [14]. Since 1940, the drug to treat leprosy was dapsone, but today a multidrug scheme is recommended [14]. Ridley-Jopling classification uses histopathological and clinical features and the bacteriological index as well. It classifies leprosy in 
tuberculoid (TT), borderline tuberculoid (BT), borderline (BB), borderline-lepromatous (BL), and lepromatous (LL) categories. The different categories usually correlate with host immune response. Indeterminate leprosy is an earlier nondefined state $[9,15]$. TT patients present a limited number of hypopigmented, anesthetic skin lesions with microscopically undistinguishable bacteria. The correlated $\mathrm{T}_{\mathrm{H}} 1-$ cell-mediated immune (CMI) response (IL-2, IL-6, IL-12, IFN- $\gamma$, and TNF) promotes the formation of delineated granulomas-central areas of infected macrophages, often fused into multinucleate giant cells, surrounded by $\mathrm{T}$ cellswhich suggested function in infection control is still controversial $[16,17]$ and data on M. marinum suggesting a role in infection dissemination seems interesting to test in human leprosy [18]. Conversely, LL cases present numerous sensitive or anesthetic skin lesions with high bacillary loads. LL if untreated may slowly progress to bacteremia [14]. The correlated $\mathrm{T}_{\mathrm{H}}$ 2-antibody response (IL-4, IL-5, IL-10) impedes granuloma formation, allowing for uncontrolled bacterial replication and continuous infiltration of the skin and nerves. Borderline forms, that is, borderline-tuberculoid $(\mathrm{BT})$, borderline (BB), and borderline-lepromatous (BL), comprise the majority of cases. These individuals present intermediate clinical and histological phenotypes resulting from immunologically unstable responses [7]. The incubation period between infection and clinical disease can vary from some months to up to 30 years, with a mean period of 4 years for TT and 10 years for LL [19].

\subsection{WHO Operational Classification: Multibacillary and Pau-} cibacillary. Another leprosy classification proposed by the World Health Organization (WHO) recognizes the paucibacillary $(\mathrm{PB})$ and multibacillary $(\mathrm{MB})$ forms, in which the patient presents with 1-5 skin lesions and 6 or more, respectively [20]. Patients with PB disease present very low bacterial counts, exhibiting localized infection and lesions characterized by expression of type $1\left(\mathrm{~T}_{\mathrm{H}} 1\right) \mathrm{T}$ helper lymphocyterelated cytokines (cell-mediated immunity) as IL-2, IL-6, IL12 , IFN- $\gamma$, and TNF. Patients presenting MB form are more susceptible to the pathogen and exhibit systemic infection and lesions expressing $\mathrm{T}_{\mathrm{H}} 2$ cytokines (humoral immunity) $[2,7,21]$. Multibacillary leprosy roughly includes BB, BL, and LL forms, and paucibacillary the TT and BT forms [7, 21]. For a complete table of polymorphisms associated with leprosy types according to WHO classification, see Table 1.

\section{Immunological Reactions and Nerve Damage in Leprosy}

3.1. Mitsuda Response. The standard measure of cell mediated immunity (CMI) against M. leprae is the Mitsuda response [4], a delayed granulomatous skin reaction elicited by the intradermal injection of heat-killed Mycobacterium leprae formulations-lepromin is one example - and measured 21 to 28 days after inoculation [21]. Although the Mitsuda test has been developed to assess immune response to live $M$. leprae in natural conditions of infection, other microbial agents influence this test, such as live bacille Calmette-Guerin
(BCG) vaccine, and M. tuberculosis. Therefore, the Mitsuda test reflects the ability to develop an immune granuloma after mycobacterial infection but is not a marker for specific immune responses to the leprosy bacillus and is not related to clinical variant in leprosy patients [13].

3.2. Type I Reactions: Reversal Reaction. Reversal reactions (RRs, oka type I reactions) represent the acute immune episodes of $\mathrm{T}_{\mathrm{H}} 1$ inflammatory response to $M$. leprae antigens that occur in skin and/or nerves and are the leading cause of neurological impairment in leprosy patients. The skin lesions become acutely inflamed and oedematous and may ulcerate. Oedema of the hands, feet, and face can also be a feature of a reaction, but systemic symptoms are unusual. They occur most frequently in borderline categories (BL, BT, BB) with a frequency of $30 \%$ in these patients [9] or in $\mathrm{MB}$ patients, and age is a relevant additional risk factor for both RR occurrence and sequelae after RR treatment [32]. RR are frequently recurrent and this can lead to nerve damage. RR can occur at any time but are frequently seen after starting multidrug therapy (MDT) or during the puerperium [9].

3.3. Type II Reactions: Erythema Nodosum Leprosum. Erythema nodosum leprosum (ENL) has a prevalence in leprosy patients of $24 \%$. ENL is a systemic immune reaction which can occur in LL (up to $50 \%$ of LL cases) and borderline patients (9\% of $\mathrm{BL}$ patients) and is postulated to be caused by extravascular deposition of immune complexes (ICs) resulting in neutrophil infiltration and complement activation. (See $C 3$ and $C 4 B$ genes below.) There are three subclinical types of ENL, named single acute ENL ( $8 \%$ of cases), multiple acute ENL (repeated discrete episodes), and chronic ENL (continuous, longer, and more severe episodes, $62.5 \%$ of cases) [33]. ENL affects many organs with an acute onset but it can evolve into a chronic phase and it can be recurrent. ENL produces fever and in the skin painful tender red papules or nodules which occur in crops often affecting the face and extensor surfaces of the limbs. The lesions may be superficial or deep causing a panniculitis. Bullous ENL has been described and lesions may ulcerate. Subcutaneous tissue involvement may lead to tethering and fixation to joints causing loss of function. ENL reactions may also produce uveitis, neuritis, arthritis, dactylitis, lymphadenitis, and orchitis. The prolonged inflammation of organs can lead to blindness and sterility. A greater infiltration of the skin and a higher bacterial index are two relevant risks for developing ENL [9]. Improved strategies for treatment and management of these reactions need to be developed [33].

3.4. Nerve Damage. Peripheral nerve damage is an important issue in leprosy clinical complication that diminish quality of life of patients [34]. Nerve involvement in leprosy affects sensory, motor, and autonomic function of peripheral nerves. Acute neuritis leads to nerve function impairment, which if not treated timely and adequately leads to permanent loss of nerve function causing peripheral sensory and motor neuropathy [9]. The mechanism underlying nerve injury in leprosy is poorly understood [35]. TT patients present granulomatous inflammation of peripheral nerves causes 

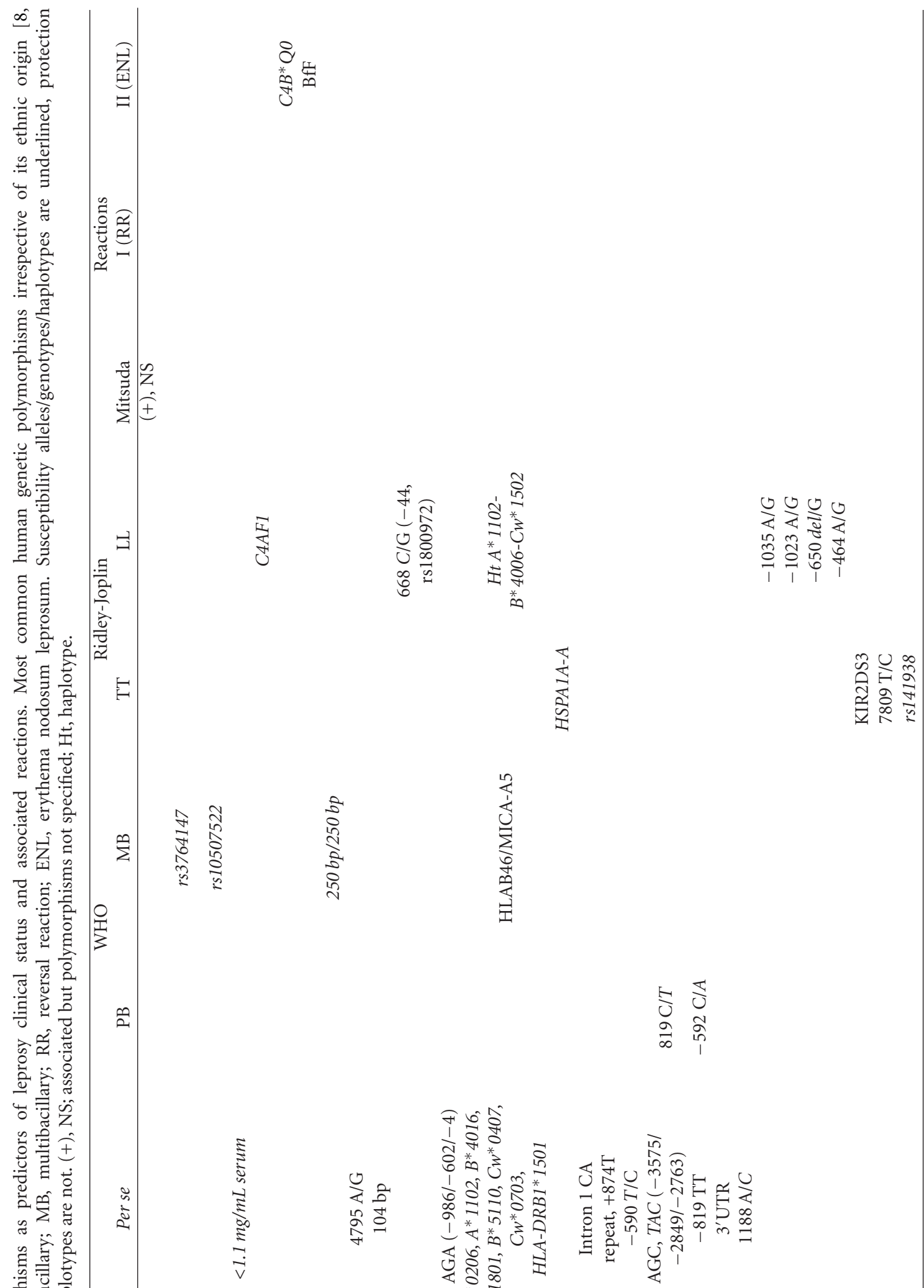

$$
\text { 旁产 }
$$

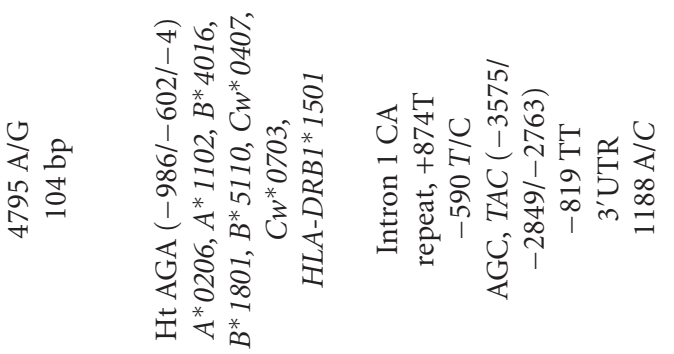




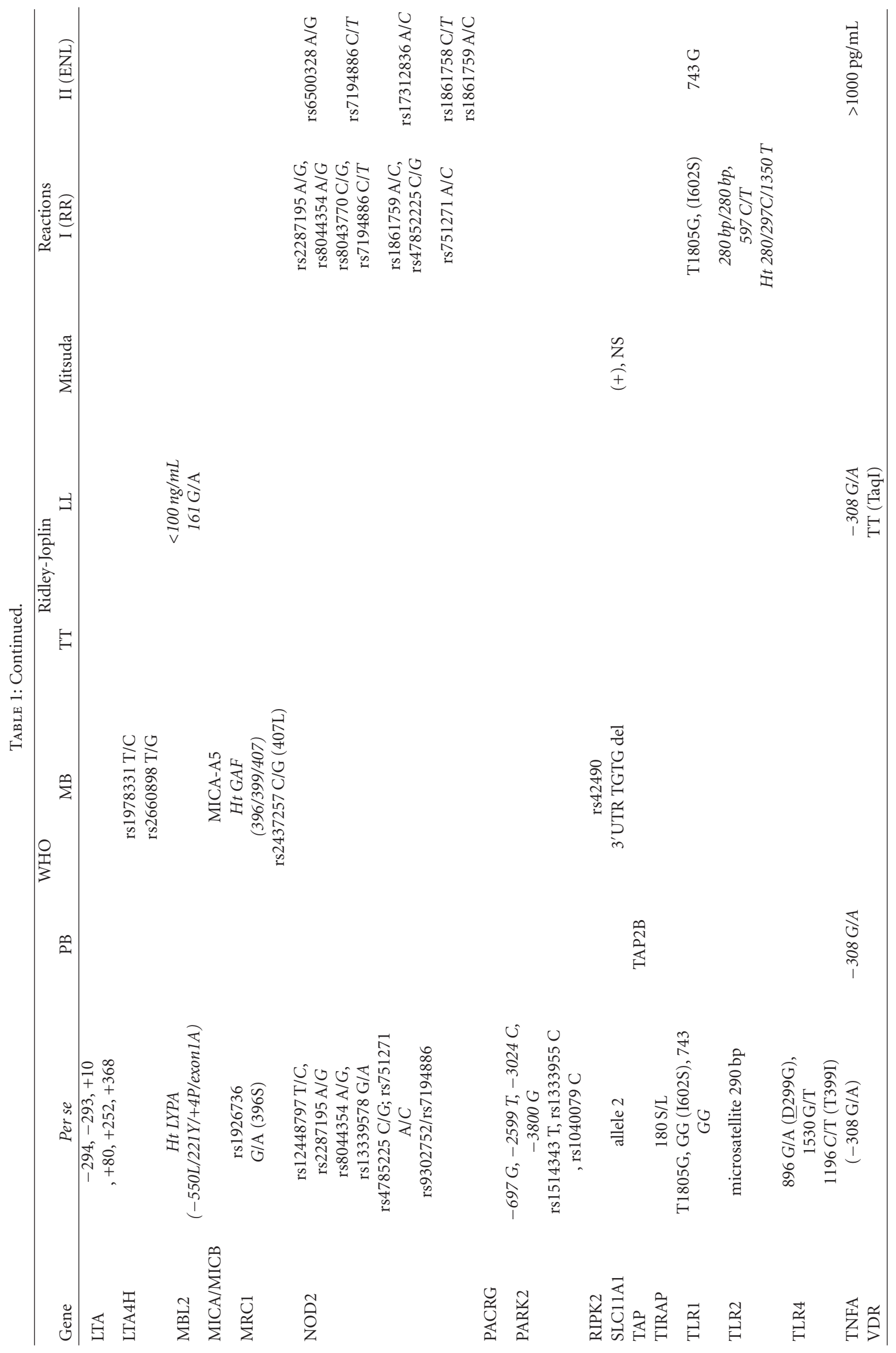


palpable enlargement, which may or may not be painful and causes sensory and motor loss in the distribution of the affected nerve. There is enlargement and infiltration of fascicles, which may show caseous necrosis [9]. In LL patients, nerve function impairment occurs earlier than in TT patients [35] the destruction of dermal nerves leads to a glove and stocking neuropathy, peripheral nerve damage occurs late. There is bacterial proliferation within the Schwann cells, which leads to foamy degeneration of the cells losing their regeneration ability [9]. This nerve damage causes deformities and disabilities are a social stigma and cause discrimination of patients and their families [34].

\section{Genes and Its Variants Associated with Leprosy Types and Immunological Reactions}

4.1. Complement Component 3 (C3,19p13.3-p13.2). Human complement component forms ester linkages with hydroxyl groups. Cleavage of C3 exposes a reactive short-lived thioester moiety in C3b, which covalently attaches to amine and carbohydrate groups on the target surface. This initial tagging is quickly amplified on foreign cells but is immediately regulated on human cells. Moreover, the reactivity of the thioester moiety to specific carbohydrates might lead to preferential opsonization of foreign particles and represent a basic pattern recognition mechanism [36, 37]. In an extrinsic protease pathway, plasmin, thrombin, elastase, and plasma kallikrein can also cleave and activate C3. Furthermore, target-bound MBL can activate $\mathrm{C} 3$ independently of mannan binding lectin serine protease 2 (MASP-2), C2, or C4 in vitro. The highly abundant C3 can act as a systemic surveillance protein that has few endogenous ligands but becomes transformed into one of the most versatile binding partners upon activation to $\mathrm{C} 3 \mathrm{~b}$. The remaining $\mathrm{C} 3 \mathrm{a}$ is a powerful chemoattractant that guides neutrophils, monocytes, and macrophages toward sites of complement activation and induces TLR activation in antigen presenting cells [37]. Phenolic glycolipid 1, a major component of $M$. leprae cell wall and activated complement component $\mathrm{C} 3$, are exposed on the cell membrane of $M$. leprae-infected human dendritic cells. C3 costimulate naïve T cells via CD46 thus induce the differentiation of IL-10-secreting regulatory $\mathrm{T}$ cells. In this way, $M$. leprae subverts host natural immunity to provoke an adaptive response that favors bacillary survival [38]. In populations from Ethiopia and Mali, it was found that mean C3 serum concentration was lower in leprosy patients $(0.88 \mathrm{mg} / \mathrm{mL}$ in Ethiopic and $0.73 \mathrm{mg} / \mathrm{mL}$ in patients from Mali) when compared with nonleprosy subjects $(1.1 \mathrm{mg} / \mathrm{mL}$, both populations) being the lowest $\mathrm{C} 3$ levels in each population found in BL patients $(0.62 \mathrm{mg} / \mathrm{mL})$ and in TT patients $(0.81 \mathrm{mg} / \mathrm{mL})$ from Mali and Ethiopic populations, respectively. Otherwise $\mathrm{C} 3$ phenotypes designated according to electrophoretic mobility FF (fast-fast), FS (fast-slow), and SS (slow-slow) were not associated with leprosy. Correlation of both variables were not reported [22].

4.2. Complement Component 4 B (C4B, $6 p 21.3)$. In the classical pathway or antibody-dependent pathway of complement,
C1s component cleaves C4 into C4a and opsonin C4b, thereby exposing a previously hidden thioester and leading to covalent deposition of $\mathrm{C} 4 \mathrm{~b}$ on surfaces in the immediate vicinity of the activation sites (opsonization) [37]. Deficiency of the $\mathrm{C} 4 \mathrm{~b}$ isoprotein with higher binding capacity for thiol groups has been found in association with Immuno Complexes (IC) diseases involving bacterial or fungal antigens. The non expressed allele $C 4 B^{*} Q 0$ increases risk of ENL probably because C4b is involved in opsonization of pathogens and immune complex clearance [39] interacting with C3b and CR1 (CD35) to promote neutrophil-mediated phagocytosis [37].

4.3. Collagen Type III, Alpha 1 (COL3A1, 2q31). Type III collagen is a fibrillar-forming collagen comprising $3 \alpha-1$ chains and it is expressed throughout embryogenesis. In adult, type III collagen is an essential component of the extracellular matrix in a variety of internal organs and skin. Mutations in COL3A1 gene cause type III and type IV EhlersDanlos syndrome, a condition of remarkable skin and joint plasticity that often leads to major blood vessels rupture in early adult life [40]. Patients homozygous for 250-bp COL $3 A 1$ procollagen III alpha I in Indian population were associated with the $\mathrm{MB}$ form of the disease [23]. A probable linkage with SCL11A1 located at the neighbor locus 2q35 has been suggested [24].

4.4. Human $\beta$-Defensin 1 (DEFB1, 8p23.1). The human $\beta$ defensin $1(\mathrm{hBD}-1)$ has been associated with different allergic and infectious diseases as well as cancer with a relevant biological function in protecting mothers against lactational mastitis and breast-fed infants from diarrhea. In addition, hBD-1 is capable of chemoattract human immature dendritic cells (iDCs) and memory $\mathrm{T}$ cells in vitro, promotes caspase-mediated apoptosis of cancer cells, and its expression correlates with insulin and glucose levels [41]. In a Mexican population DEFB1 gene was associated with LL, the SNP $668 \mathrm{C}$ alters one out of five putative binding sites for nuclear factor kappa B1 (NF- $\kappa$ B1 or p50/p105) $[2,41]$ and functionally correlates with lower constitutive expression but surprisingly also with higher IFN- $\gamma$-dependent inducibility of both hBD-1 and hBD-3 [42]. Thus, diminished NF- $\kappa$ Bdependent constitutive expression caused by $668 \mathrm{C}$, could be a risk factor for developing leprosy into LL been suggested that this allele is more permissive to $M$. leprae dissemination in patients already infected [2]. This probably explains the extremely rare heterozygote advantage DEFB1 promoter [41, $43,44]$ and recurrent overrepresentation of heterozygotes in this locus $[45,46]$.

4.5. Ficolin 2 (FCN2, 9q34.3). Ficolin 2 (also called L-ficolin or hucolin) is a soluble pattern-recognition molecule that binds to different pathogen-associated molecular patterns (PAMPs), such as lipoteichoic acid, carbohydrates and acetylated groups, initiating activation complement through lectin pathway leading to pathogen phagocytosis [37]. Functional haplotypes of polymorphisms that produce normal ficolin-2 level protect against clinical leprosy, and low 
serum levels of circulating protein are clearly associated with promoter polymorphisms $-986,-602,-4$ [47].

4.6. Major Histocompatibility Complex Class I and II (HLA, 6p21.3). The main function of major histocompatibility complex (MHC) is antigen presentation of processed antigens to T cells. Each classical HLA class I gene encodes a transmembrane $\alpha$-chain that noncovalently associates with $\beta-2$ microglobulin $(B 2 M, 15 \mathrm{q} 21-\mathrm{q} 22.2)$. The heterodimeric class I molecule, expressed on all nucleated cells, presents cytosolic pathogen-associated peptide to $\mathrm{CD}^{+} \mathrm{T}$ cells. In addition, the classical HLA class I molecules (HLA-A, -B, and $-C$ ) bind peptides of intracellular origin and present them to $\mathrm{CD}^{+} \mathrm{T}$ cells, engaging killer cell immunoglobulinlike receptors (KIRs) expressed on natural killer cells been this as NK "licensing" that render the death of M. lepraeinfected cells [48]. The heterodimeric class II molecule, expressed on B cells and antigen-presenting cells, presents extracellular or intravesicular pathogen-associated peptide to $\mathrm{CD}^{+}{ }^{+} \mathrm{T}$ cells $\left(\mathrm{T}_{\mathrm{H}} 1\right.$ and $\left.\mathrm{T}_{\mathrm{H}} 2\right)$ resulting in cytokine production [7]. Polymorphisms in human leukocyte antigens (HLA)-class I (A, B, C) and class II (DR, DQ) have been associated with leprosy types. HLA-DR polymorphisms modulate the cytokine profile of $\mathrm{CD}^{+} \mathrm{T}$ from TT and LL forms against $M$. leprae-derived heat shock proteins [49]. HLAs polymorphisms in as HLA $A^{*} 0206, A^{*} 1102$, $B^{*} 4016, B^{*} 1801, B^{*} 5110, C w^{*} 0407$, and $C w^{*} 0703$ have been associated with leprosy and HLA $A^{*} 0101, C w^{*} 04011$, and $C w^{*} 0602$ were associated with protection in Indian population. Haplotype $A^{*} 1102-B^{*} 4006-\mathrm{Cw}^{*} 1502$ was found in association with LL patients. Haplotypes $A^{*} 1102-B^{*} 4006-$ $\mathrm{CW}^{*} 0407$ and $\mathrm{A}^{*} 0203-\mathrm{B}^{*} 4016-\mathrm{Cw}^{*} 0703$ were increased in both LL and TT patients [50]. HLA-class I antigens $A 9$, $A 10, A 32, B 5, B 21, B w 4, B w 6, C w 1, C w 2$, and HLA-class II antigens $D R 9, D R 10, D R w 52, D Q 1, D Q 3$ were associated with leprosy. HLA-class I antigens A3, B44, B49, and HLAclass II antigen $D Q 5$ were found protective in a Turkish population [51]. HLA-B46 allele and HLAB46/MICA-A5 haplotype protects against $\mathrm{MB}$ leprosy in Chinese population [52]. In Chinese and Indian populations, HLA-DRB1/HLA$D Q A 1$ locus, particularly $H L A-D R B 1^{*} 1501$ was associated with leprosy [6]. Nevertheless, the interpretation of linkage and association studies of the HLA complex requires caution because of long-range LD [7].

4.7. Interferon Gamma (IFNG, 12q15). Interferon-gamma (IFN- $\gamma$ ), or type II interferon, is a cytokine critical for innate and adaptive immunity against viral and intracellular bacterial infections and for tumor control. Aberrant IFNG expression is associated with a number of autoinflammatory and autoimmune diseases. The importance of IFNG in the immune system stems in part from its ability to inhibit viral replication directly, but most importantly it derives from its immunostimulatory and immunomodulatory effects. IFN$\gamma$ is produced predominantly by natural killer (NK) and natural killer $\mathrm{T}$ (NKT) cells as part of the innate immune response, and by $\mathrm{CD} 4$ and $\mathrm{CD} 8$ cytotoxic $\mathrm{T}$ lymphocyte (CTL) effector $\mathrm{T}$ cells once antigen-specific immunity develops [53]. Low levels of IFN- $\gamma$ in response to $M$. leprae antigen in household contacts of $\mathrm{MB}$ patients predict leprosy infection [54]. In a Brazilian population, there was a protective effect for $+874 \mathrm{~T}$ SNP carriers in IFNG, a gene also previously reported to be associated with tuberculosis [55].

4.8. Interleukin 4 (IL-4, 5q31.1). Interleukin-4 (IL-4), a $\mathrm{T}_{\mathrm{H}} 2$ cytokine, regulates expression of a C-type lectin, CD209 antigen (also called Dendritic Cell-Specific Intercellular Adhesion Molecule 3-Grabbing Nonintegrin, DC SIGN), and subsequent $M$. leprae internalization by Schwann cells [56]. IL-4 is expressed in skin lesions of MB patients [56] and its $-590 \mathrm{C}$ allele decreases leprosy susceptibility [57]. IL4 has been shown to act downregulating TLR2 and IL-10 on monocytes. IL-10 suppresses production of IL-12 [9] and also downregulates antimycobacterial peptide cathelicidin (LL-37) [58] apparently in a negative feedback mechanism [59].

4.9. Mannose-Binding Lectin 2 (MBL2, 10q21.1). Mannose binding lectin 2 (MBL2) is an important component of the first-line defense against infections. MBL2 acts as a pattern recognition molecule of a wide range of infectious agents recognizing sugar moieties such as mannose, $\mathrm{N}$-acetyl glucosamine, fucose, and glucose present on the surface of several microorganisms, leading to their phagocytosis and MBL-associated protease-2-dependent activation of complement [60] through mannan binding lectin serine proteases (MASPs) such as MASP2 [61]. MBL also can induce phagocytosis in the absence of complement activation through an interaction with one or more collectin receptors [62] and is able to induce inflammatory responses by binding to receptors on phagocytes [60]. MBL deficiency, which mainly results from three relatively common single-point mutations in exon 1, reduces phagocytosis and internalization of intracellular pathogens protecting the host against intracellular infections such as leprosy and interestingly predisposes both to infection by extracellular pathogens and to autoimmune disease [60]. A significant negative association of MBL deficiency $(<100 \mathrm{ng} / \mathrm{mL})$ was observed with LL patients when compared with controls and TT patients, suggesting a protective role for MBL deficiency against the development of the most severe MB form of leprosy [63] explained because MBL deficiency could be advantageous against intracellular pathogens that exploit complement deposition on their surface to enhance uptake into phagocytes such as the case of $M$. leprae $[14,60]$. SNP G161A was associated with protection from LL and C154T as well as $G 170 A$ show no association in a population from Nepal [64]. The LYPA haplotype of MBL2 was associated with susceptibility to leprosy per se and to progression to the lepromatous and borderline forms of the disease in subjects from southern Brazil [25]. Recently, it has been shown that MBL serum levels in leprosy patients are influenced by age, those patients aged $>40$ years had decreased MBL levels compared with patients aged $\leq 40$ years. No association was found among analyzed SNPs in MBL2 with leprosy susceptibility or with any of its clinical forms [65]. 
4.10. Mannose Receptor, C-Type 1 (MRC1, 10p12.33). The first genome-wide linkage leprosy study revealed a high LOD score in locus 10p13 among Indian populations [66]. Mannose receptor 1 gene (MRC1 or CD206) in this locus, specifically $10 \mathrm{p} 12.33$, codifies for mannose receptor C-type lectin (MR) on macrophages membranes, which recognize M. leprae cell wall mannose residues, as well as ovalbumin and zymosan. Notably, cellular entry through MR has been correlated with $M$. tuberculosis virulence [67]. From 75 analyzed SNPs in MRC1 (101.8 Kb), G396S (rs1926736) was the only relevant. 3965 allele of MRC1 is the only nonsynonymous polymorphism of exon 7 and was associated with protection against MB leprosy in 490 simplex and 90 multiplex Vietnamese families (704 patients). Similarly, but in haplotype analysis, when $399 \mathrm{~A}$ and $407 \mathrm{~F}$ polymorphisms are present, $396 \mathrm{G}$ allele was also the risk factor in a casecontrol study of Brazilian patients with MB leprosy. It has been suggested that MR-M.leprae interaction is modulated by an additional accessory host molecule of unknown identity [68].

\subsection{Nucleotide Oligomerization Domain 2 (NOD2, 16q12).} Nucleotide oligomerization domain 2 (NOD2, also called caspase recruitment domain-contanining protein 15, CARD15) is part of intracellular PAMPs known as NODlike receptors (NLRs). Triggered by muramyl dipeptide recognition, NOD2 interacts with the adapter protein RIPK2 (but not with pyrin domain containing-3, NALP3, another member of NOD-like receptor family) to initiate NF- $\kappa \mathrm{B}$ pathway signaling through the recruitment of the inhibitor of NF- $\kappa$ B kinase (IKK) complex to the central domain of RIPK2 $[6,69]$. NOD2 interacts with the autophagy-related gene 16L1 (ATG16L1) and seems to be relevant inducing the autophagosome complex assembly (ATG5-ATG12) which induces autophagy in DCs leading to bacterial handling and generation of MHC class II antigen-specific $\mathrm{CD} 4^{+}$ $\mathrm{T}$ cell responses in DCs. The polymorphisms rs9302752 and rs7194886 were associated with leprosy in Chinese population [26] but not in Indian or Mali population [70].

\subsection{Parkin 2 and Parkin 2 Coregulated Gene (PARK2 and} PACRG, 6q25.2-q27). PARK2 (parkin) encodes an E3 ubiquitin ligase, with a role in the ubiquitin-proteasome pathway of intracellular protein degradation. PARK2 also regulates the processing of protein antigens within macrophages, thereby affecting antigen presentation [35] and it is involved in cellular antioxidant response and T cell anergy [71]. PARK2 was named for its association with an early-onset form of Parkinson disease [35]. PARK2 is not only expressed in dopaminergic neurons but also in monocyte-derived macrophages and Schwann cells, primary host cells of $M$. leprae [71]. PACRG is a Parkin-coregulated neighbor gene of unknown function $[12,72]$ but together with PARK2 have been proposed to be involved in degradation of TLRs and NF- $\kappa \mathrm{B}$ signaling pathway proteins [71].

In families from Southern Vietnam was reported a leprosy susceptibility region in $6 \mathrm{p} 25$. Of seven microsatellite markers underlying the linkage peak, alleles of two markers (D6S1035 and D6S305) showed strong evidence for association with leprosy [72]. In a study of 197 simplex Vietnamese families, from 81 SNPs analyzed, 19 SNPs clustered in the $5^{\prime} P A R K 2$ and $P A C R G$ regulatory region and were significantly associated with leprosy. Common allele $T$ of the first intron of PACRG, PARK2_e01 (-2599), and rare allele $C$ of $r s 1040079$ were independently associated with an increased risk of leprosy and solely this two Tag SNPs explain the strong association in this region [12]. The association was reproduced in a Brazilian population (587 cases, 388 controls) where possession of as few of two of the 17 risk alleles was highly predictive of leprosy. Again, PARK2_e01 (-2599) and rs1040079 were among the three most significantly associated SNPs in this population [12].

4.13. Solute Carrier Family 11, Member 1 (SLC11A1, 2q35). SLC11A1 is expressed in spleen, lung, liver, and most intensively, in peripheral blood leukocytes [14]. SLC11A1(formerly NRAMP1) is a divalent cation transporter, when a live bacteria is phagocytosed. SLC11A1 protein is recruited to the macrophage phagosome membrane and limits pathogens' iron availability by exporting it from the phagolysosome $[73,74]$. It has been suggested that SLC11A1 may influence the expression of MHC class II molecules, regulation of expression of TNFA, and induction of nitric oxide synthase [35]. By a genome-wide scan in Vietnamese families, it was found linkage with Mitsuda response in SLC11A1 (2q35) and 17q21-25 loci, two regions previously linked to mycobacterial infection, granulomatous, [75] as well as early onset $[76,77]$ and severe asthma [78]. These similarities suggest that some common exacerbated epithelial responses may be regulated by SLC11A1 and also by a major unidentified gene(s) in 17q21-25 [75]. The $3^{\prime}$ UTR TGTG deletion in SLC11A1 was associated with MB subtype in a Mali population and heterozygotes were more frequent among MB than PB patients $[79,80]$. It has been proposed that allele 2 of the SLC11A1 promoter is an independent genetic factor that predisposes cells to enable pathogen survival, probably due to its low efficiency in iron transport, but establishment of the infection and disease development are probably conditioned by additional genetic factors [81].

4.14. Toll-Like Receptor 1 (TLR1, 4p14). Toll-like receptors are cell-surface molecules that play an important role in the recognition of pathogens $[35,82]$. TRL1: TLR2 heterodimers recognize triacyl lipopeptides from Gram-negative bacteria and mycoplasma, two of the three lipid chains of the triacylated lipopeptide interact with TLR2 and the third chain binds the hydrophobic channel of TLR1 and lead to NF- $\kappa$ B activation [82]. The association between the hypofunctional TLR1 phenotype and protection against leprosy suggests that M. leprae may utilize TLR1 as part of its pathogenic mechanism [6]. The T1805G (rs5743618 or I602S) variant presumably downregulates TLR1 expression on the cell surface and also causes abnormal signaling [83, 84] and has been associated with a decreased incidence of leprosy and with protection against reversal reaction [83] probably diminishing antimycobacterial cathelicidin (LL-37) 
expression $[4,5]$. Allele $1805 G$ has been associated with diminished production of IL- $1 \beta$, IL- 6 , and TNF in peripheral blood mononuclear cells stimulated with $M$. leprae $[84,85]$. TLR1 248SS is associated with protection against leprosy [86].

4.15. Toll-Like Receptor 2 (TLR2, 4q32). TLR2 is involved in the recognition of a wide range of pathogen-associated molecular patterns (PAMPs) as lipoarabinomannan from mycobacteria, lipopeptides from bacteria, peptidoglycan and lipoteichoic acid from Gram-positive bacteria, zymosan from fungi, tGPI-mucin from Trypanosoma cruzi and the hemagglutinin protein from measles virus [82], and in combination with MARCO and CD14 recognizes mycobacterial trehalose 6, 6' -dimycolate (TDM/cord factor) [87]. Lipoproteins trigger host responses via TLR2. TLR2: TLR6 heterodimers are activated by diacylated lipoproteins from Gram-positive bacteria and mycoplasma and TRL2:TLR1 by triacylated lipoproteins. Both heterodimers form a mshaped structure and induce mainly inflammatory cytokines [82]. Furthermore, this increased ability to generate diversity in PAMP recognition-forming dimers with TLR1 or TLR6, TLR2 also has the ability to act together with other coreceptors on the cell surface that assist PAMP recognition. These include dectin-1, a $\mathrm{C}$ type lectin that binds fungus $\beta$-glucan and induces internalization and CD36, which act together with TLR2-TLR6 heterodimer to mediate the sensing of some but not all TLR2 agonists [82]. TLR-dependent IL$12 \mathrm{p} 40$ production was detected from primary human monocytes and monocyte-derived DCs after stimulation with a 19- or 33-kDa M. leprae lipopeptide [88]. However, some TLR2 nonsynonymous polymorphisms in Japanese patients were not associated with leprosy [89] probably because their variants are in a dispensable region of the receptor. Nonsynonymous substitution R677W of TLR2 gene was found in 10 out of $45 \mathrm{LL}$ patients but absent in TT or nonlepromatous controls [90]. A study in Indian population reveals that the supposed mutation is in a pseudogene located $23 \mathrm{~Kb}$ upstream of TLR2, who shares 93\% homology with its exon 3 [91]. A synthetic lipopeptide consisting of N-terminal portion of $M$. leprae $19-\mathrm{kDa}$ lipoprotein triggered and increased the number of apoptotic Schwann cell line ST88-14 by a TLR2-mediated mechanism causing nerve damage [92]. Also, homozygosity for the 280-bp microsatellite in TLR2 gene strongly increased the risk of RR in Ethiopian patients [93].TLR2 and TLR1 expression was relatively much weaker in LL skin biopsies [88].

4.16. Toll-Like Receptor 4 (TLR4, 9q32-q33). TLR4 is a cellsurface receptor which recognizes respiratory syncytial virus fusion proteins, Streptococcus pneumoniae pneumolysin, mouse mammary tumor virus envelope proteins, and plantderived cytostatic drug paclitaxel, also in complex with MD2+ engages bacterial lipopolysaccharide (LPS). There are two main possible routes of TLR4 activation, the direct route that leads to an early $\mathrm{NF}-\kappa \mathrm{B}$ response and inflammatory cytokines expression and the indirect route through endosome leading to a subpathway of late NF- $\kappa \mathrm{B}$ activation and inflammatory cytokines profiles and to an alternative subpathway where Interferon Response Factor 3 (IRF3) induces type I IFN expression [82]. TLR4 is required for the host defense against $M$. tuberculosis and probably mediate response to mycobacterial heat shock proteins [4]. Furthermore, stimulation of monocytes with $M$. leprae partially inhibited their subsequent response to LPS. SNPs 896 G/A (D299G) and 1196 C/T (T399I) were associated with protection against leprosy in Ethiopic patients [94].

4.17. Tumor Necrosis Factor (TNF, 6p21.3). Tumor necrosis factor is a proinflammatory and immunostimulatory cytokine secreted predominantly by monocytes/macrophages that has effects on lipid metabolism, coagulation, insulin resistance, and endothelial function [14]. High levels of circulating TNF ( $>1000 \mathrm{pg} / \mathrm{mL}$ ) have been demonstrated in the plasma of some individuals with ENL who also develop erythema multiforme, a skin disease characterized by papular or vesicular lesions and reddening or discoloration of the skin often in concentric zones about the lesions [27]. In vitro peripheral blood mononuclear cells (PBMCs) from individuals with ENL secrete the highest amounts of TNF following stimulation with lipoarabinomannan, the main component of cell wall, when compared with other forms of the disease. It has been reported that half of BT patients have elevated serum levels of TNF [27].

4.18. Vitamin D Receptor (VDR, 12q12-q14). Upregulation of the Vitamin D receptor gene (VDR) on macrophages is associated with increased intracellular killing of $M$. tuberculosis. In human monocytes and macrophages, the 25hydroxyvitamin D3-1a-hydroxylase (CYP27B1) which converts the 25, D into the active 1, 25 form, upregulating and activating the vitamin $\mathrm{D}$ receptor and downstream induction of the antimicrobial peptide, cathelicidin [5] which is active against M. tuberculosis [95-98] and could be also active in vivo against $M$. leprae, but this deserves further investigation $[2,41]$. In Indian population, homozygotes for the alternate alleles have been associated with LL and TT, respectively [99], and in Mexican population TT genotype of VDR obtained with TaqI (exon 9, codon 352) has been associated with LL [100].

\section{Potential but Scarcely Explored Candidate Genes}

5.1. Hydroxyacid Oxidase 1 Gene (HAO1, 20p12). The marker D20S115 in locus 20p12 that was associated with leprosy in Indian population [10] lies near atopic dermatitis with asthma loci (ATOD3) and also associated with psoriasis [101]. The closest gene to the marker D20S115 in locus 20p12 $(\sim 0.2 \mathrm{Mb})$ is HAO1, hydroxyacid oxidase 1 [102]. This enzyme is expressed predominantly in the liver and pancreas and utilizes a flavin cofactor to convert glycolate and 2-hydroxy fatty acids with the concomitant reduction of molecular oxygen to hydrogen peroxide [103]. It could be worthwhile to analyze its role in leprosy, especially in LL patients, whose lesions accumulate host-derived oxidized lipids [4], knowing that M. leprae has lost most of the genes 
involved in the detoxification of reactive oxygen and nitrogen species [104] and have a unique truncated hemoglobin [105, 106].

5.2. Toll-Like Receptor 6 (TLR6, 4p14). TLR6 is a cell-surface receptor and TLR6:TLR4 heterodimer with coreceptor CD36 recognizes oxidized low-density lipoprotein (ox-LDL), a known danger-associated molecular pattern (DAMP) [82]. TLR6 regulates $M$. leprae-Schwann cells interactions, and mainly in LL lesions, leads to phagocytosis and subsequent signaling for induction of lipid droplets (LDs or lipid bodies) biogenesis in infected cells, LDs favor mycobacterial survival and persistence, and thus are a hallmark of the foamy phenotype of M. leprae-infected Schwann cells [107]. LL lesions have a marked upregulation of host lipid metabolism genes when compared with TT lesions. Virchow cells (lepra cells or foam cells) are macrophages containing intracellular accumulation of a specific host-derived oxidized phospholipid, 1-palmitoyl-2-(5, 6-epoxyisoprostane E2)-snglycero-3-phosphorylcholine (PEIPC) [4]. Theoretically, if TLR6 is mutated at its heterodimerization site it could not form the TLR2:TLR6, and the subsequent recognition of PAMPs or DAMPs should be abrogated. This epistasis should be considered in studies of TLR2 [82]. Biomedical relevant TLR6 polymorphisms remain to be discovered and a bioinformatic transcriptional impact could be used as a polymorphism sieving method [108].

5.3. Toll-Like Receptor 8 (TLR8, Xp22.3-p22.2). TLR8 is expressed exclusively in intracellular vesicles such as the endoplasmic reticulum, endosomes, lysosomes, and endolysosomes, where it recognized microbial nucleic acids. TLR8 is expressed in various tissues with the highest expression in monocytes and is upregulated after bacterial infection. TLR8 mediates the recognition of R-848 and viral ssRNA but this function seems to overlap with TLR7 [82]. Four polymorphisms in TLR8 showed protection against TB [4] and it will be worthwhile to assess them in leprosy susceptibility. Furthermore, their localization in a sexual chromosome could be relevant in gender-associated susceptibilities (leprosy prevalence presents male: female ratio of 1.5-2.0:1) [19] and X-linked heritabilities, although no linkage of leprosy susceptibility with the $\mathrm{X}$ chromosome has been found to date [109].

\section{Further Considerations in Leprosy Immunogenetics}

6.1. Homo Sapiens-M. Leprae Genetic Interaction and Treatment Effect. With the above mentioned, it is now clear that most of the variants in clinical states in leprosy could be due to host genetics $[2,7,8,24,110-112]$, and it is also relevant to study whether $M$. leprae variants [104, 110-116] and its genetic interaction with human genome accounts for some clinical variability, specially for drug-resistant leprosy in M. leprae genes folP1, rpoB, and gyrA which are associated with resistance to dapsone, rifampicin, and ofloxacin respectively $[117,118]$. Also of relevant importance is the effect of immunosuppressive drugs on leprosy reactions [35].

6.2. Ethnic Susceptibility Differences due to Genetic Background and Technical Bias. It is relevant to mention that the ethnic genetic pool can affect susceptibility to disease [119] for example, the significant differences of polymorphism frequencies in DEFB1 gene among Mexican population when compared with German and Chinese populations [46], which gene, as above mentioned was associated with LL [2]. It will be worthwhile to carry out susceptibility studies in other populations and be cautious with meta-analysis results in leprosy, because the relevancy of a gene in the disease could be influenced to allele/genotypes/haplotypes frequencies according to ethnic background $[119,120]$.

A relevant issue of concern is due to technical limitations, for example, the fact that commercial microarrays do not contain all relevant probes for SNPs associated with leprosy and many biomedical important polymorphisms are poorly represented. These technical limitations lead to a bias in the scientific interpretation of results and this issue is usually not mentioned in genome-wide association studies (GWASs) and authors still claim for a "complete genome" analysis [121].

\section{Efficient Prevention, Fast Diagnostics, and Successful Therapeutics, the Goal of Translational Medicine: Leprosy as an Example}

One potential application of genetic association studies' conclusions could be a starting point to a better understanding of disease by proposing candidate genes to be assessed with in vitro and in vivo studies, and also to evaluate the relative impact of genetic variants related to ethnicity versus environmental factors, in order to design better alternative diagnostics and therapeutics that could solve the public health problem that leprosy still represents.

Nevertheless, an imminent effect in patients with genetic testing information could be distress and anxiety so this information must be handled wisely by researchers and clinicians [122] because education plays a crucial role in the management of leprosy, is relevant to carefully explain to the affected individual and their family the infectious nature of the disease, and is curable [9]. Now with information availability from the ongoing 1000 Genomes $[123,124]$ and Human Variome projects the situation claims priority, and ethical standards must be established, reviewed, and updated constantly [125].

One recent and promising proposal in infectious diseases treatment comprising leprosy is the administration of antimicrobial peptide elicitors (APEs) specifically with the posibility of upregulating antimicobacterial host defense peptides as hBD-1 $[41,126]$ and cathelicidin LL-37 [127, 128] or the classical approach of APs direct administration [129], in the latter case with its inherent drawbacks [41]. Effectiveness and safety of APEs or APs in clinical practice is an exciting upcoming event. Even though the leprosy 
morbid map is far from complete, this is just one potential application that must be moved from bench to bedside.

\section{Acknowledgments}

This work is dedicated to the loving memory of Mr. Luis Jorge Prado Rosas. This review was supported by the Fondos Sectoriales de Ciencia Básica SEP-CONACYT (CB-2008-01105813, Mexico). The author receives a research stimulus from the Sistema Nacional de Investigadores (SNI 41290, CONACYT, Mexico). Thanks to Drs. A. Rougemont, J. D. Lambris, M. T. Mira, E. Schurr, R. L. Modlin, and S. Akira for kindly sharing some of their published work. Thanks to Elizabeth Sugg and Dr. Kirk Allen (Peace Corps/CIATEJ, AC) for reviewing the manuscript and two anonymous referees to provide helpful suggestions.

\section{Disclosure}

The author declares no conflicts of interest.

\section{References}

[1] M. Orlova, T Di Pietrantonio, and E. Schurr, "Review: genetics of infectious diseases: hidden etiologies and common pathways," Clinical Chemistry and Laboratory Medicine, vol. 49, no. 9, pp. 1427-1437, 2011.

[2] E. Prado Montes de Oca, J. S. Velarde-Felix, J. J. Ríos-Tostado, V. J. Picos-Cardenas, and L. E. Figuera, "SNP 668C (-44) alters a NF- $\kappa \mathrm{B} 1$ putative binding site in non-coding strand of human $\beta$-defensin 1 (DEFB1) and is associated with lepromatous leprosy," Infection, Genetics and Evolution, vol. 9, no. 4, pp. 617-625, 2009.

[3] D. M. Scollard, "Leprosy research declines, but most of the basic questions remain unanswered," International Journal of Leprosy and Other Mycobacterial Diseases, vol. 73, pp. 25-27, 2005.

[4] R. L. Modlin, "The innate immune response in leprosy," Current Opinion in Immunology, vol. 22, no. 1, pp. 48-54, 2010.

[5] D. Montoya and R. L. Modlin, "Learning from leprosy: insight into the human innate immune response," Advances in Immunology, vol. 105, pp. 1-24, 2010.

[6] F. O. Vannberg, S. J. Chapman, and A. V. Hill, "Human genetic susceptibility to intracellular pathogens," Immunological Reviews, vol. 240, no. 1, pp. 105-116, 2011.

[7] A. Alter, A. Grant, L. Abel, A. Alcais, and E. Schurr, "Leprosy as a genetic disease," International Mammalian Genome Society, vol. 22, no. 1-2, pp. 19-31, 2011.

[8] C. C. Cardoso, A. C. Pereira, C. de Sales Marques, and M. O. Moraes, "Leprosy susceptibility: genetic variations regulate innate and adaptive immunity, and disease outcome," Future Microbiology, vol. 6, no. 5, pp. 533-549, 2011.

[9] S. L. Walker and D. N. Lockwood, "The clinical and immunological features of leprosy," British Medical Bulletin, vol. 77-78, no. 1, pp. 103-121, 2006.

[10] K. Tosh, S. Meisner, M. R. Siddiqui et al., "A region of chromosome 20 is linked to leprosy susceptibility in a South Indian population," The Journal of Infectious Diseases, vol. 186, no. 8, pp. 1190-1193, 2002.

[11] M. A. Shaw, I. J. Donaldson, A. Collins et al., "Association and linkage of leprosy phenotypes with HLA class II and tumour necrosis factor genes," Genes and Immunity, vol. 2, no. 4, pp. 196-204, 2001.

[12] M. T. Mira, A. Alcais, H. Van Thuc et al., "Susceptibility to leprosy is associated with PARK2 and PACRG," Nature, vol. 427, no. 6975, pp. 636-640, 2004.

[13] B. Ranque, A. Alcais, N. V. Thuc et al., "A recessive major gene controls the Mitsuda reaction in a region endemic for leprosy," The Journal of Infectious Diseases, vol. 192, no. 8, pp. 1475-1482, 2005.

[14] M. T. Mira, "Genetic host resistance and susceptibility to leprosy," Microbes and Infection, vol. 8, no. 4, pp. 1124-1131, 2006.

[15] D. S. Ridley and W. H. Jopling, "Classification of leprosy according to immunity. A five-group system," International Journal of Leprosy and Other Mycobacterial Diseases, vol. 34, no. 3, pp. 255-273, 1966.

[16] M. Mariano, "The experimental granuloma. A hypothesis to explain the persistence of the lesion," Revista do Instituto de Medicina Tropical de Sao Paulo, vol. 37, no. 2, pp. 161-176, 1995.

[17] C. L. Crawford and P. M. Hardwicke, "Experimental leprosy: a model of epithelioid cell granuloma," International Journal of Dermatology, vol. 50, no. 3, pp. 255-261, 2011.

[18] J. M. Davis and L. Ramakrishnan, "The role of the granuloma in expansion and dissemination of early tuberculous infection," Cell, vol. 136, no. 1, pp. 37-49, 2009.

[19] W. J. Britton and D. N. Lockwood, "Leprosy," The Lancet, vol. 363, no. 9416, pp. 1209-1219, 2004.

[20] S. L. Walker, L. Whittam, F. Vega-Lopez, and D. N. Lockwood, "Milia complicating successfully treated cutaneous leishmaniasis in three children," The British Journal of Dermatology, vol. 155, no. 4, pp. 860-861, 2006.

[21] E. A. Misch, W. R. Berrington, J. C. Vary Jr., and T. R. Hawn, "Leprosy and the human genome," Microbiology and Molecular Biology Reviews, vol. 74, no. 4, pp. 589-620, 2010.

[22] D. P. Agarwal, H. G. Benkmann, H. W. Goedde et al., "Levels of serum $\beta 1 \mathrm{C} / \beta 1 \mathrm{~A}$ globulin (C3) and its polymorphism in leprosy patients and healthy controls from Ethiopia and Mali," Humangenetik, vol. 21, no. 4, pp. 355-359, 1974.

[23] G. Kaur, G. Sachdeva, L. K. Bhutani, and R. Bamezai, "Association of polymorphism at COL3A and CTLA4 loci on chromosome 2q31-33 with the clinical phenotype and in-vitro CMI status in healthy and leprosy subjects: a preliminary study," Human Genetics, vol. 100, no. 1, pp. 4350, 1997.

[24] J. Fitness, K. Tosh, and A. V. S. Hill, "Genetics of susceptibility to leprosy," Genes and Immunity, vol. 3, no. 8, pp. 441-453, 2002.

[25] I. J. de Messias-Reason, A. B. Boldt, A. C. Braga et al., "The association between mannan-binding lectin gene polymorphism and clinical leprosy: new insight into an old paradigm," The Journal of Infectious Diseases, vol. 196, no. 9, pp. 1379-1385, 2007.

[26] F. R. Zhang, W. Huang, S. M. Chen et al., "Genomewide association study of leprosy," The New England Journal of Medicine, vol. 361, no. 27, pp. 2609-2618, 2009.

[27] E. N. Sarno, G. E. Grau, L. M. Vieira, and J. A. Nery, "Serum levels of tumour necrosis factor- $\alpha$ and interleukin- $1 \beta$ during leprosy reactional states," Clinical and Experimental Immunology, vol. 84, no. 1, pp. 103-108, 1991.

[28] A. R. Santos, P. N. Suffys, P. R. Vanderborght et al., "Role of tumor necrosis factor- $\alpha$ and interleukin-10 promoter gene polymorphisms in leprosy," The Journal of Infectious Diseases, vol. 186, no. 11, pp. 1687-1691, 2002. 
[29] L. Hamann, O. Kumpf, R. P. Schuring et al., "Low frequency of the TIRAP S180L polymorphism in Africa, and its potential role in malaria, sepsis, and leprosy," BMC Medical Genetics, vol. 10, article 65, 2009.

[30] A. Alvarado-Navarro, M. Montoya-Buelna, J. F. Munoz-Valle, R. I. Lopez-Roa, C. Guillen-Vargas, and M. Fafutis-Morris, “The 3'UTR 1188 A/C polymorphism in the interleukin$12 \mathrm{p} 40$ gene (IL-12B) is associated with lepromatous leprosy in the west of Mexico," Immunology Letters, vol. 118, no. 2, pp. 148-151, 2008.

[31] S. Roy, W. McGuire, C. G. Mascie-Taylor et al., "Tumor necrosis factor promoter polymorphism and susceptibility to lepromatous leprosy," The Journal of Infectious Diseases, vol. 176, no. 2, pp. 530-532, 1997.

[32] B. Ranque, V. T. Nguyen, H. T. Vu et al., "Age is an important risk factor for onset and sequelae of reversal reactions in Vietnamese patients with leprosy," Clinical Infectious Diseases, vol. 44, no. 1, pp. 33-40, 2007.

[33] L. Pocaterra, S. Jain, R. Reddy et al., "Clinical course of erythema nodosum leprosum: an 11-year cohort study in Hyderabad, India," The American Journal of Tropical Medicine and Hygiene, vol. 74, no. 5, pp. 868-879, 2006.

[34] A. Alcais, M. Mira, J. L. Casanova, E. Schurr, and L. Abel, "Genetic dissection of immunity in leprosy," Current Opinion in Immunology, vol. 17, no. 1, pp. 44-48, 2005.

[35] D. M. Scollard, L. B. Adams, T. P. Gillis, J. L. Krahenbuhl, R. W. Truman, and D. L. Williams, "The continuing challenges of leprosy," Clinical Microbiology Reviews, vol. 19, no. 2, pp. 338-381, 2006.

[36] A. Sahu, T. R. Kozel, and M. K. Pangburn, "Specificity of the thioester-containing reactive site of human $\mathrm{C} 3$ and its significance to complement activation," Biochemical Journal, vol. 302, part 2, pp. 429-436, 1994.

[37] D. Ricklin, G. Hajishengallis, K. Yang, and J. D. Lambris, "Complement: a key system for immune surveillance and homeostasis," Nature Immunology, vol. 11, no. 9, pp. 785797, 2010.

[38] D. Callegaro-Filho, N. Shrestha, A. E. Burdick, and P. A. Haslett, "A potential role for complement in immune evasion by Mycobacterium leprae," Journal of Drugs in Dermatology, vol. 9, no. 11, pp. 1373-1382, 2010.

[39] I. J. de Mesias, J. Santamaria, M. Brenden, A. Reis, and G. Mauff, "Association of C4B deficiency (C4B*Q0) with erythema nodosum in leprosy," Clinical and Experimental Immunology, vol. 92, no. 2, pp. 284-287, 1993.

[40] X. Liu, H. Wu, M. Byrne, S. Krane, and R. Jaenisch, “Type III collagen is crucial for collagen I fibrillogenesis and for normal cardiovascular development," Proceedings of the National Academy of Sciences of the United States of America, vol. 94, no. 5, pp. 1852-1856, 1997.

[41] E. Prado Montes de Oca, "Human $\beta$-defensin 1: a restless warrior against allergies, infections and cancer," International Journal of Biochemistry and Cell Biology, vol. 42, no. 6, pp. 800-804, 2010.

[42] A. A. Kalus, L. P. Fredericks, B. M. Hacker et al., "Association of a genetic polymorphism $(-44 \mathrm{C} / \mathrm{G} \mathrm{SNP})$ in the human DEFB1 gene with expression and inducibility of multiple $\beta$ defensins in gingival keratinocytes," BMC Oral Health, vol. 9, article 21, 2009.

[43] E. Prado Montes de Oca, "DEFB1 (defensin, beta 1) (8p23.1)," Atlas of Genetics and Cytogenetics in Oncology and Haematology, vol. 15, article 2, 2011.
[44] R. Cagliani, M. Fumagalli, S. Riva et al., "The signature of long-standing balancing selection at the human defen $\sin \beta-1$ promoter," Genome Biology, vol. 9, no. 9, article R143, 2008.

[45] E. Prado Montes de Oca, A. García-Vargas, R. LozanoInocencio et al., "Association of $\beta$-defensin 1 single nucleotide polymorphisms with atopic dermatitis," International Archives of Allergy and Immunology, vol. 142, no. 3, pp. 211218, 2007.

[46] E. Prado Montes de Oca, H. Rangel-Villalobos, M. P. Gallegos-Arreola, L. Sandoval, and L. E. Figuera, "SNPs in human $\beta$-defensin 1 gene (DEFB1): frequencies in a Mexican population and new PCR-RFLPs assays," International Journal of Immunogenetics, vol. 33, no. 5, pp. 339-342, 2006.

[47] I. de Messias-Reason, P. G. Kremsner, and J. F. Kun, "Functional haplotypes that produce normal ficolin-2 levels protect against clinical leprosy," The Journal of Infectious Diseases, vol. 199, no. 6, pp. 801-804, 2009.

[48] S. Kulkarni, M. P. Martin, and M. Carrington, "The Yin and Yang of HLA and KIR in human disease," Seminars in Immunology, vol. 20, no. 6, pp. 343-352, 2008.

[49] G. Fabozzi, G. Modiano, F. Poccia, F. Visca, and F. Ascenzi, "Is there an answer? Is there a genetic basis for human susceptibility to leprosy?” IUBMB Life, vol. 57, pp. 119-121, 2005.

[50] U. Shankarkumar, K. Ghosh, S. Badakere, and D. Mohanty, "Novel HLA class I alleles associated with Indian leprosy patients," Journal of Biomedicine and Biotechnology, vol. 2003, no. 3, pp. 208-211, 2003.

[51] M. Kocak, M. Balci, B. Pence, and N. Kundakci, "Associations between human leukocyte antigens and leprosy in the Turkish population," Clinical and Experimental Dermatology, vol. 27, no. 3, pp. 235-239, 2002.

[52] L. M. Wang, A. Kimura, M. Satoh, and S. Mineshita, "HLA linked with leprosy in southern China; HLA-linked resistance alleles to leprosy," International Journal of Leprosy and Other Mycobacterial Diseases, vol. 67, no. 4, pp. 403-408, 1999.

[53] J. R. Schoenborn and C. B. Wilson, "Regulation of interferon$\gamma$ during innate and adaptive immune responses," Advances in Immunology, vol. 96, pp. 41-101, 2007.

[54] E. P. Sampaio, A. L. Moreira, G. Kaplan et al., "Mycobacterium leprae-induced interferon- $\gamma$ production by household contacts of leprosy patients: association with the development of active disease," The Journal of Infectious Diseases, vol. 164, no. 5, pp. 990-993, 1991.

[55] C. C. Cardoso, A. C. Pereira, V. N. Brito-De-Souza et al., "IFNG $+874 \mathrm{~T}>\mathrm{A}$ single nucleotide polymorphism is associated with leprosy among Brazilians," Human Genetics, vol. 128, no. 5, pp. 481-490, 2010.

[56] R. M. Teles, S. R. Krutzik, M. T. Ochoa, R. B. Oliveira, E. N. Sarno, and R. L. Modlin, "Interleukin-4 regulates the expression of CD209 and subsequent uptake of Mycobacterium leprae by Schwann cells in human leprosy," Infection and Immunity, vol. 78, no. 11, pp. 4634-4643, 2010.

[57] D. Yang, H. Song, W. Xu et al., "Interleukin 4-590T/C Polymorphism and Susceptibility to Leprosy," Genetic Testing and Molecular Biomarkers. In press.

[58] M. D. Howell, N. Novak, T. Bieber et al., "Interleukin-10 downregulates anti-microbial peptide expression in atopic dermatitis," The Journal of Investigative Dermatology, vol. 125, no. 4, pp. 738-745, 2005.

[59] J. Yu, N. Mookherjee, K. Wee et al., "Host defense peptide LL37 , in synergy with inflammatory mediator IL- $1 \beta$, augments immune responses by multiple pathways," The Journal of Immunology, vol. 179, no. 11, pp. 7684-7691, 2007. 
[60] D. L. Jack, N. J. Klein, and M. W. Turner, "Mannose-binding lectin: targeting the microbial world for complement attack and opsonophagocytosis," Immunological Reviews, vol. 180, pp. 86-99, 2001.

[61] S. Thiel, T. Vorup-Jensen, C. M. Stover et al., "A second serine protease associated with mannan-binding lectin that activates complement," Nature, vol. 386, no. 6624, pp. 506510, 1997.

[62] D. L. Jack and M. W. Turner, "Anti-microbial activities of mannose-binding lectin," Biochemical Society Transactions, vol. 31, no. 4, pp. 753-757, 2003.

[63] L. N. Dornelles, L. Pereira-Ferrari, and I. Messias-Reason, "Mannan-binding lectin plasma levels in leprosy: deficiency confers protection against the lepromatous but not the tuberculoid forms," Clinical and Experimental Immunology, vol. 145, no. 3, pp. 463-468, 2006.

[64] B. R. Sapkota, M. Macdonald, W. R. Berrington et al., "Association of TNF, MBL, and VDR polymorphisms with leprosy phenotypes," Human Immunology, vol. 71, no. 10, pp. 992-998, 2010.

[65] L. R. Vasconcelos, J. P. Fonseca, R. F. Carmo et al., "Mannosebinding lectin serum levels in patients with leprosy are influenced by age and MBL2 genotypes," International Journal of Infectious Diseases, vol. 15, no. 8, pp. e551-e557, 2011.

[66] M. R. Siddiqui, S. Meisner, K. Tosh et al., "A major susceptibility locus for leprosy in India maps to chromosome 10p13," Nature Genetics, vol. 27, no. 4, pp. 439-441, 2001.

[67] L. S. Schlesinger, T. M. Kaufman, S. Iyer, S. R. Hull, and L. K. Marchiando, "Differences in mannose receptor-mediated uptake of lipoarabinomannan from virulent and attenuated strains of Mycobacterium tuberculosis by human macrophages," The Journal of Immunology, vol. 157, no. 10, pp. 4568-4575, 1996.

[68] A. Alter, L. de Leseleuc, N. Van Thuc et al., "Genetic and functional analysis of common MRC1 exon 7 polymorphisms in leprosy susceptibility," Human Genetics, vol. 127, no. 3, pp. 337-348, 2010.

[69] R. Cooney, J. Baker, O. Brain et al., "NOD2 stimulation induces autophagy in dendritic cells influencing bacterial handling and antigen presentation," Nature Medicine, vol. 16, no. 1, pp. 90-97, 2010.

[70] S. H. Wong, A. V. Hill, and F. O. Vannberg, "Genomewide association study of leprosy," The New England Journal of Medicine, vol. 362, no. 15, pp. 1446-1447, 2010.

[71] E. Schurr, A. Alcais, L. de Leseleuc, and L. Abel, "Genetic predisposition to leprosy: a major gene reveals novel pathways of immunity to Mycobacterium leprae," Seminars in Immunology, vol. 18, no. 6, pp. 404-410, 2006.

[72] M. T. Mira, A. Alcais, N. Van Thuc et al., "Chromosome $6 \mathrm{q} 25$ is linked to susceptibility to leprosy in a Vietnamese population," Nature Genetics, vol. 33, no. 3, pp. 412-415, 2003.

[73] N. Jabado, A. Jankowski, S. Dougaparsad, V. Picard, S. Grinstein, and P. Gros, "Natural resistance to intracellular infections: natural resistance-associated macrophage protein 1 (Nramp1) functions as a $\mathrm{pH}$-dependent manganese transporter at the phagosomal membrane," Journal of Experimental Medicine, vol. 192, no. 9, pp. 1237-1248, 2000.

[74] S. Gruenheid and P. Gros, "Genetic susceptibility to intracellular infections: nramp1, macrophage function and divalent cations transport," Current Opinion in Microbiology, vol. 3, no. 1, pp. 43-48, 2000.

[75] B. Ranque, A. Alter, M. Mira et al., "Genomewide linkage analysis of the granulomatous mitsuda reaction implicates chromosomal regions $2 \mathrm{q} 35$ and $17 \mathrm{q} 21$," The Journal of Infectious Diseases, vol. 196, no. 8, pp. 1248-1252, 2007.

[76] E. Bouzigon, E. Corda, H. Aschard et al., "Effect of 17q21 variants and smoking exposure in early-onset asthma," The New England Journal of Medicine, vol. 359, no. 19, pp. 19851994, 2008.

[77] M. F. Moffatt, I. G. Gut, F. Demenais et al., "A large-scale, consortium-based genomewide association study of asthma," The New England Journal of Medicine, vol. 363, no. 13, pp. 1211-1221, 2010.

[78] A. Binia, N. Khorasani, P. K. Bhavsar et al., "Chromosome 17q21 SNP and severe asthma," Journal of Human Genetics, vol. 56, no. 1, pp. 97-98, 2011.

[79] L. Abel, F. O. Sánchez, J. Oberti et al., "Susceptibility to leprosy is linked to the human NRAMP1 gene," The Journal of Infectious Diseases, vol. 177, no. 1, pp. 133-145, 1998.

[80] S. J. Meisner, S. Mucklow, G. Warner, S. O. Sow, C. Lienhardt, and A. V. S. Hill, "Association of nramp1 polymorphism with leprosy type but not susceptibility to leprosy per se in West Africans," The American Journal of Tropical Medicine and Hygiene, vol. 65, no. 6, pp. 733-735, 2001.

[81] F. R. Ferreira, L. R. Goulart, H. D. Silva, and I. M. B. Goulart, "Susceptibility to leprosy may be conditioned by an interaction between the NRAMP1 promoter polymorphisms and the lepromin response," International Journal of Leprosy and Other Mycobacterial Diseases, vol. 72, no. 4, pp. 457-467, 2004.

[82] T. Kawai and S. Akira, "The role of pattern-recognition receptors in innate immunity: update on toll-like receptors," Nature Immunology, vol. 11, no. 5, pp. 373-384, 2010.

[83] C. M. Johnson, E. A. Lyle, K. O. Omueti et al., "Cutting edge: a common polymorphism impairs cell surface trafficking and functional responses of TLR1 but protects against leprosy," The Journal of Immunology, vol. 178, no. 12, pp. 7520-7524, 2007.

[84] E. A. Misch, M. Macdonald, C. Ranjit et al., "Human TLR1 deficiency is associated with impaired mycobacterial signaling and protection from leprosy reversal reaction," Plos Neglected Tropical Diseases, vol. 2, no. 5, Article ID e231, 2008.

[85] E. A. Misch and T. R. Hawn, "Toll-like receptor polymorphisms and susceptibility to human disease," Clinical Science, vol. 114, no. 5-6, pp. 347-360, 2008.

[86] R. P. Schilling, L. Hamann, W. R. Faber et al., "Polymorphism $\mathrm{N} 248 \mathrm{~S}$ in the human Toll-like receptor 1 gene is related to leprosy and leprosy reactions," The Journal of Infectious Diseases, vol. 199, no. 12, pp. 1816-1819, 2009.

[87] D. M. Bowdish, K. Sakamoto, M. J. Kim et al., "MARCO, TLR2, and CD14 are required for macrophage cytokine responses to mycobacterial trehalose dimycolate and $\mathrm{Myco-}$ bacterium tuberculosis," Plos Pathogens, vol. 5, no. 6, Article ID e1000474, 2009.

[88] S. R. Krutzik, M. T. Ochoa, P. A. Sieling et al., "Activation and regulation of Toll-like receptors 2 and 1 in human leprosy," Nature Medicine, vol. 9, no. 5, pp. 525-532, 2003.

[89] N. Mikita, N. Kanazawa, M. Ozaki et al., "No involvement of non-synonymous TLR2 polymorphisms in Japanese leprosy patients," Journal of Dermatological Science, vol. 54, no. 1, pp. 48-49, 2009.

[90] T. J. Kang and G. T. Chae, "Detection of Toll-like receptor 2 (TLR2) mutation in the lepromatous leprosy patients," FEMS Immunology and Medical Microbiology, vol. 31, no. 1, pp. 5358, 2001. 
[91] D. Malhotra, V. Relhan, B. S. Reddy, and R. Bamezai, "TLR2 Arg677Trp polymorphism in leprosy: revisited," Human Genetics, vol. 116, no. 5, pp. 413-415, 2005.

[92] R. B. Oliveira, M. T. Ochoa, P. A. Sieling et al., "Expression of toll-like receptor 2 on human schwann cells: a mechanism of nerve damage in leprosy," Infection and Immunity, vol. 71, no. 3, pp. 1427-1433, 2003.

[93] P. Y. Bochud, T. R. Hawn, M. R. Siddiqui et al., "Tolllike receptor 2 (TLR2) polymorphisms are associated with reversal reaction in leprosy," The Journal of Infectious Diseases, vol. 197, no. 2, pp. 253-261, 2008.

[94] P. Y. Bochud, D. Sinsimer, A. Aderem et al., "Polymorphisms in toll-like receptor 4 (TLR4) are associated with protection against leprosy," European Journal of Clinical Microbiology and Infectious Diseases, vol. 28, no. 9, pp. 1055-1065, 2009.

[95] P. T. Liu, S. Stenger, H. Li et al., "Toll-like receptor triggering of a vitamin D-mediated human antimicrobial response," Science, vol. 311, no. 5768, pp. 1770-1773, 2006.

[96] P. T. Liu, S. Stenger, D. H. Tang, and R. L. Modlin, "Cutting edge: vitamin $\mathrm{D}$-mediated human antimicrobial activity against Mycobacterium tuberculosis is dependent on the induction of cathelicidin," The Journal of Immunology, vol. 179, no. 4, pp. 2060-2063, 2007.

[97] A. R. Martineau, S. M. Newton, K. A. Wilkinson et al., "Neutrophil-mediated innate immune resistance to mycobacteria," The Journal of Clinical Investigation, vol. 117, no. 7, pp. 1988-1994, 2007.

[98] A. R. Martineau, K. A. Wilkinson, S. M. Newton et al., "IFN- $\gamma$ - and TNF-independent vitamin D-inducible human suppression of mycobacteria: the role of cathelicidin LL-37," The Journal of Immunology, vol. 178, no. 11, pp. 7190-7198, 2007.

[99] S. Roy, A. Frodsham, B. Saha, S. K. Hazra, C. G. N. MascieTaylor, and A. V. S. Hill, "Association of vitamin D receptor genotype with leprosy type," The Journal of Infectious Diseases, vol. 179, no. 1, pp. 187-191, 1999.

[100] J. S. Velarde Felix, S. G. Cazarez Salazar, R. Castro Velazquez, J. G. Rendon Maldonado, and H. Rangel Villalobos, "Association between the TaqI polymorphism of Vitamin D Receptor gene and lepromatous leprosy in a Mexican population sample," Salud Publica de Mexico, vol. 51, no. 1, pp. 59-61, 2009.

[101] W. O. Cookson, B. Ubhi, R. Lawrence et al., "Genetic linkage of childhood atopic dermatitis to psoriasis susceptibility loci," Nature Genetics, vol. 27, no. 4, pp. 372-373, 2001.

[102] E. Prado Montes de Oca, Human b-defensin 1 (DEFB1) polymorphisms in leprosy susceptibility, Ph.D. thesis, Guadalajara University, 2007.

[103] J. M. Jones, J. C. Morrell, and S. J. Gould, "Identification and characterization of HAOX1, HAOX2, and HAOX3, three human peroxisomal 2-hydroxy acid oxidases," The Journal of Biological Chemistry, vol. 275, no. 17, pp. 12590-12597, 2000.

[104] S. T. Cole, K. Eiglmeier, J. Parkhill et al., "Massive gene decay in the leprosy bacillus," Nature, vol. 409, no. 6823, pp. 1007$1011,2001$.

[105] P. Visca, G. Fabozzi, M. Milani, M. Bolognesi, and P. Ascenzi, "Nitric oxide and Mycobacterium leprae pathogenicity," IUBMB Life, vol. 54, no. 3, pp. 95-99, 2002.

[106] P. Visca, G. Fabozzi, A. Petrucca et al., "The truncated hemoglobin from Mycobacterium lepraeq," Biochemical and Biophysical Research Communications, vol. 294, no. 5, pp. 1064-1070, 2002.

[107] K. A. Mattos, V. G. C. Oliveira, H. D’Avila et al., “TLR6driven lipid droplets in Mycobacterium leprae-infected
Schwann cells: immunoinflammatory platforms associated with bacterial persistence," The Journal of Immunology, vol. 187, no. 5, pp. 2548-2558, 2011.

[108] G. N. López Campos, W. Li, and E. Prado Montes de Oca, "A novel in silico method for transcriptional impact assessment of polymorphisms in eukaryotes: variants in human antimicrobial peptides promoters as an example," submitted.

[109] E. N. Miller, S. E. Jamieson, M. Fakiola et al., "Genomewide scans for leprosy and tuberculosis susceptibility genes in Brazilians," Genes and Immunity, vol. 5, no. 1, pp. 63-67, 2004.

[110] T. Gillis, V. Vissa, M. Matsuoka et al., "Characterisation of short tandem repeats for genotyping Mycobacterium leprae," Leprosy Review, vol. 80, no. 3, pp. 250-260, 2009.

[111] M. Matsuoka, A. V. Gonzalez, I. Estrada, C. CarrenoMartinez, and M. Fafutis-Morris, "Various genotypes of Mycobacterium leprae from Mexico reveal distinct geographic distribution," Leprosy Review, vol. 80, no. 3, pp. 322326, 2009.

[112] M. Monot, N. Honore, T. Garnier et al., "Comparative genomic and phylogeographic analysis of Mycobacterium leprae," Nature Genetics, vol. 41, no. 12, pp. 1282-1289, 2009.

[113] Y. C. Shin, H. Lee, G. P. Walsh, J. D. Kim, and S. N. Cho, "Variable numbers of TTC repeats in Mycobacterium leprae DNA from leprosy patients and use in strain differentiation," Journal of Clinical Microbiology, vol. 38, no. 12, pp. 45354538, 2000.

[114] N. A. Groathouse, B. Rivoire, H. Kim et al., "Multiple polymorphic loci for molecular typing of strains of Mycobacterium leprae," Journal of Clinical Microbiology, vol. 42, no. 4, pp. 1666-1672, 2004.

[115] M. Monot, N. Honore, T. Garnier et al., "On the origin of leprosy," Science, vol. 308, no. 5724, pp. 1040-1042, 2005.

[116] M. Matsuoka, L. Zhang, M. F. Morris, P. Legua, and C. Wiens, "Polymorphism in the rpoT gene in Mycobacterium leprae isolates obtained from Latin American countries and its possible correlation with the spread of leprosy," FEMS Microbiology Letters, vol. 243, no. 2, pp. 311-315, 2005.

[117] M. Matsuoka, Y. Suzuki, I. E. Garcia et al., "Possible mode of emergence for drug-resistant leprosy is revealed by an analysis of samples from Mexico," Japanese Journal of Infectious Diseases, vol. 63, no. 6, pp. 412-416, 2010.

[118] M. Matsuoka, "Drug resistance in leprosy," Japanese Journal of Infectious Diseases, vol. 63, no. 1, pp. 1-7, 2010.

[119] D. Altshuler, M. J. Daly, and E. S. Lander, "Genetic mapping in human disease," Science, vol. 322, no. 5903, pp. 881-888, 2008.

[120] E. Prado Montes de Oca and W. Li, "Human $\beta$-defensin 1 (DEFB1) alleles and genotypes frequencies probably impact atopic dermatitis ethnic susceptibility," International Journal of Dermatology. In press.

[121] E. Prado Montes de Oca, "Genome-Wide Association Studies (GWAS) are not "complete genome" association studies," unpublished.

[122] L. Rew, M. Kaur, A. McMillan, M. MacKert, and D. Bonevac, "Systematic review of psychosocial benefits and harms of genetic testing," Issues in Mental Health Nursing, vol. 31, no. 10, pp. 631-645, 2010.

[123] 1000 Genomes Project Consortium, "1000 Genomes: a deep catalog of human genetic variation," August 2011, http://www.1000genomes.org. 
[124] 1000 Genomes Project Consortium, "A map of human genome variation from population-scale sequencing," Nature, vol. 467, no. 7319, pp. 1061-1073, 2010.

[125] M. R. Kohonen-Corish, J. Y. Al-Aama, A. D. Auerbach et al., "How to catch all those mutations-the report of the third human variome project meeting, UNESCO Paris, May 2010," Human Mutation, vol. 31, no. 12, pp. 1374-1381, 2010.

[126] E. Prado Montes de Oca, "Antimicrobial peptide elicitors: potential strategy against infections," Gaceta Medica de Mexico, vol. 145, no. 3, pp. 241-243, 2009.

[127] R. Raqib, P. Sarker, P. Bergman et al., "Improved outcome in shigellosis associated with butyrate induction of an endogenous peptide antibiotic," Proceedings of the National Academy of Sciences of the United States of America, vol. 103, no. 24, pp. 9178-9183, 2006.

[128] P. Sarker, S. Ahmed, S. Tiash et al., "Phenylbutyrate counteracts Shigella mediated downregulation of cathelicidin in rabbit lung and intestinal epithelia: a potential therapeutic strategy," PLoS One, vol. 6, Article ID e20637, 2011.

[129] W. J. Velden, T. M. van Iersel, N. M. Blijlevens, and J. P. Donnelly, "Safety and tolerability of the antimicrobial peptide human lactoferrin 1-11 (hLF1-11)," BMC Medicine, vol. 7, article 44, 2009. 


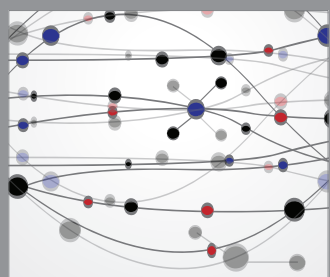

The Scientific World Journal
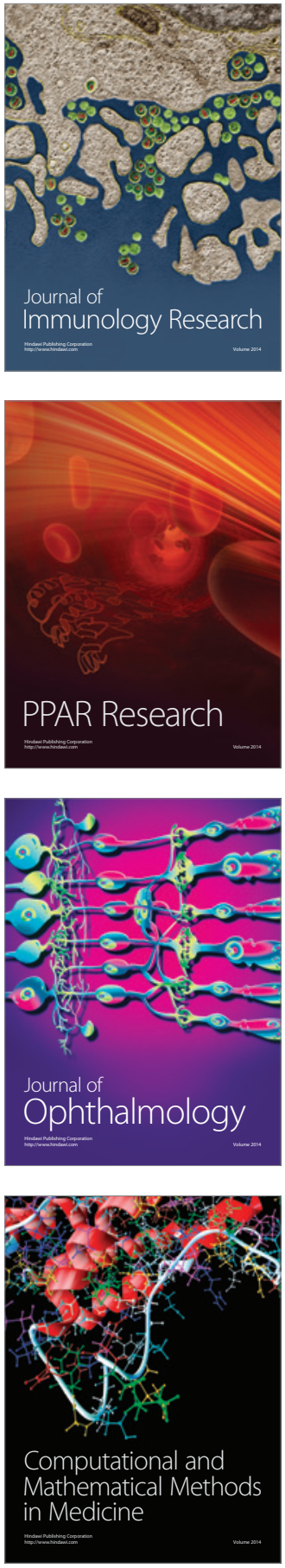

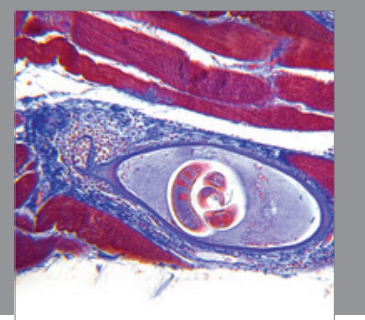

Gastroenterology

Research and Practice
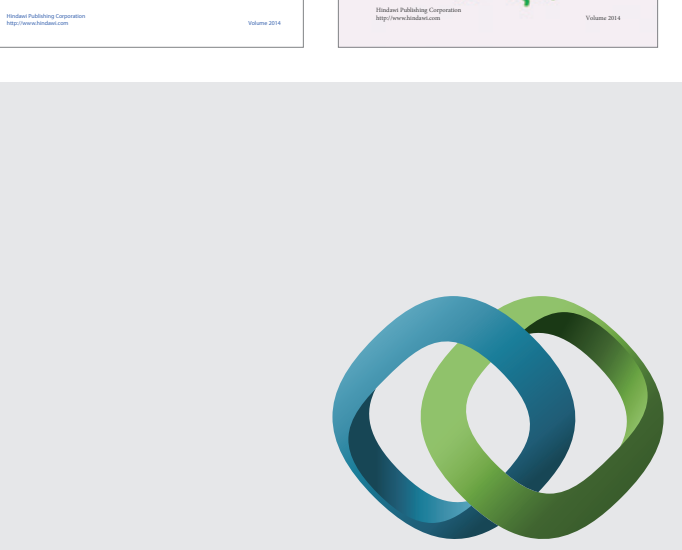

\section{Hindawi}

Submit your manuscripts at

http://www.hindawi.com
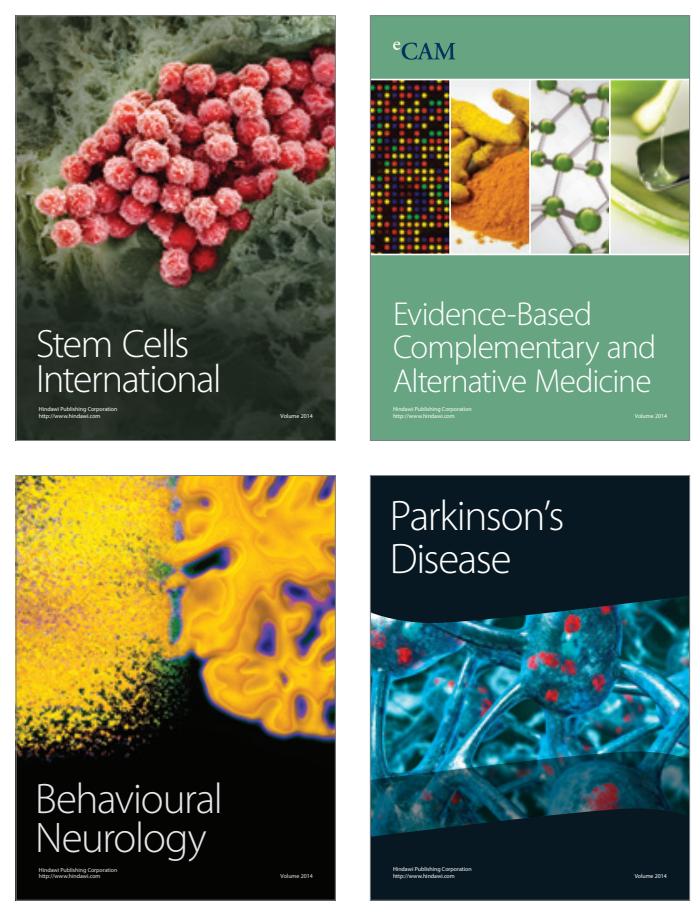

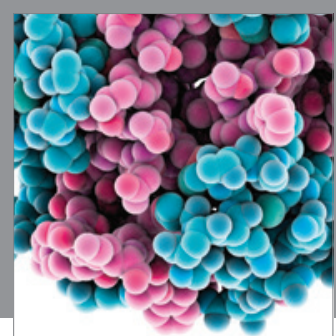

Journal of
Diabetes Research

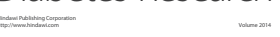

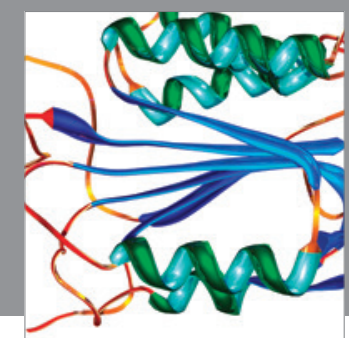

Disease Markers
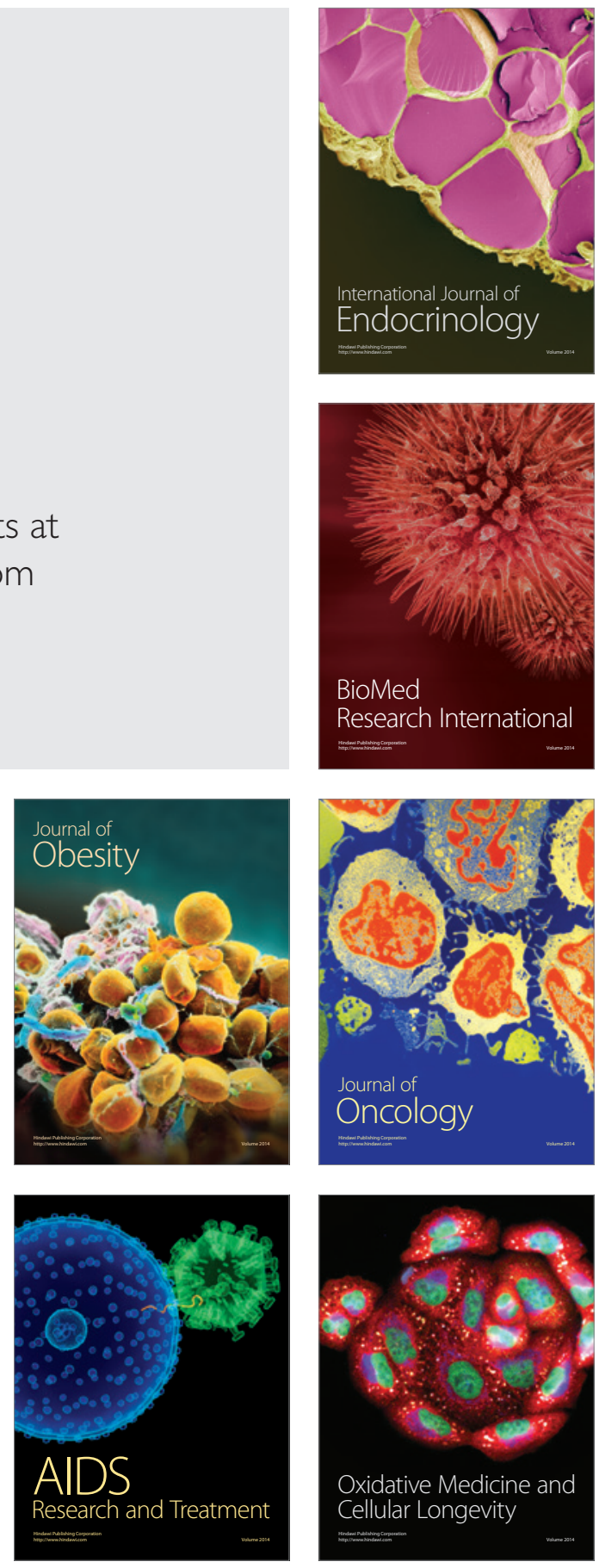